\title{
Jenis Dan Teknik Membuat Instrumen Suling Dalam Seni Karawitan Bali
}

\author{
I Wayan Suharta \\ Fakultas Seni Pertunjukan, Institut Seni Indonesia Denpasar
}

wynsuharta@gmail.com

Suling adalah instrumen aerophone, yaitu seruling bambu yang prinsipnya adalah end blow flute, memakai enam buah lubang nada, dan satu lubang pemanis untuk menimbulkan bunyi. Suling Bali memakai siwer, dan mempunyai teknik permainan yang memerlukan tiupan terus-menerus yang disebut ngunjal angkihan (circular blown breathing), dan dibuat dengan bermacam-macam ukuran, dari ukuran besar dan panjang, menengah dan sampai ukuran yang paling kecil. Dalam karawitan Bali, suling mampu memberi kesan lebih hidup dan lebih dinamis dalam melengkapi barungan gamelan Bali. Dibuat sederhana dari sebatang bambu, namun dibalik kesederhanaannya suling menunjukkan identitasnya sebagai sebuah instrumen yang sangat unik, memiliki tingkat permainan yang tinggi, aturan cara pembuatannya yang cukup rumit, serta memiliki fungsi yang cukup beragam. Tulisan ini mempergunakan pendekatan yang bersifat kualitatif, yaitu berupaya menjawab tantangan untuk memahami, memberikan interpretasi pada fenomena emperis yang dipadu dengan sistem logika dan nilai kebenaran dalam Seni Karawitan Bali. Dilaksanakan melalui tahapan-tahapan, yaitu: melakukan persiapan dan menentukan objek penelitian, menentukan lokasi penelitian, pengumpulan data, menganalisis data, dan menyajikan hasil analisis data. Mekanisme penulisannya adalah menganalisis teks yang dideskripsikan, dijadikan titik tolak untuk memahami bentuk dan jenis instrumen suling, selanjutnya menelusuri teknik membuatnya menurut pengalaman beberapa nara sumber. Tulisan mengenai suling mempunyai tujuan memperoleh pengetahuan secara deskriptif tentang suling, memperkenalkan, menggali, mendokumentasikan dan mengembangkan teknik pembuatan suling dalam karawitan Bali. Memberikan informasi dan wawasan untuk dapat memahami eksistensi suling dengan baik, serta memberi motivasi, merangsang generasi mendatang untuk lebih kreatif dan membiasakan diri agar tidak 'menganak-tirikan' salah satu instrumen gamelan Bali.

Kata kunci : suling, jenis, teknik.

\section{Types And Techniques Of Making Suling Instrument In Balinese Traditional Music}

Suling is an aerophone instrument, which is a bamboo flute whose principle is an end blow flute, uses six tones, and one sweetener to make a sound. Suling Bali uses siwer, and has a game technique that requires continuous blasting called circular blown breathing, and is made with various sizes, from large and long, medium to smallest sizes. In Balinese Karawitan, suling is able to give a more vibrant and more dynamic impression in completing the Balinese gamelan scene. Made simple from a bamboo, but behind its simplicity suling shows its identity as a very unique instrument, has a high level of play, the rules for how to make it are quite complicated, and have quite diverse functions. This paper uses a qualitative approach, which seeks to answer the challenge to understand, provides an interpretation of the emperical phenomenon combined with a system of logic and truth values in Balinese Karawitan Art. Implemented through stages, namely: make preparations and determine the object of research, determine the location of research, collect data, analyze data, and present the results of data analysis. The writing mechanism is analyzing the text described, made a starting point for understanding the shape and type of flute instruments, then tracing the technique to make it according to the experience of several resource persons. Writing on suling has the aim of obtaining descriptive knowledge about suling, introducing, exploring, documenting and developing techniques for making flutes in Balinese music. Providing information and insights to be able to understand the existence of suling well, as well as providing motivation, stimulating future generations to be more creative and accustom themselves to not 'embellish' one of the Balinese gamelan instruments.

Keywords: flute, types, techniques.

Proses Review : 1 - 20 Agustus 2019, Dinyatakan Lolos: 22 Agustus 2019 


\section{PENDAHULUAN}

Suling adalah instrumen tiup (aerophone), yaitu seruling bambu yang prinsipnya adalah end blow flute, memakai enam buah lubang nada, dan satu lubang pemanis untuk menimbulkan bunyi. Suling Bali memakai siwer, dan mempunyai teknik permainan yang memerlukan tiupan terus-menerus yang disebut dengan istilah ngunjal angkihan (circular blown breathing), dan dibuat dengan bermacam-macam ukuran, dari ukuran besar (panjang), menengah dan sampai ukuran yang paling kecil (Bandem, $1983: 56)$

Eksistensi suling dalam karawitan Bali mampu memberi kesan lebih hidup, lebih dinamis dan menarik untuk dinikmati, melengkapi barungan tertentu dalam penyajiannya. Suling dibuat sederhana dari sebatang bambu kecil, namun dibalik kesederhanaannnya suling menunjukkan identitasnya sebagai sebuah instrumen yang sangat unik; memiliki tingkat permainan yang tinggi, aturan cara pembuatannya yang cukup rumit, serta memiliki fungsi yang cukup beragam.

Dengan teknik permainan yang tinggi, tidak sembarangan orang dapat memainkan suling dengan baik. Tentunya sebagai seorang pemain suling dibutuhkan adanya kesabaran, ketekunan, kecermatan serta tanggap dalam menafsirkan melodi dan mampu memberi penjiwaan secara musikal sesuai kebutuhan dan tuntutan sebuah gending. Demikian juga untuk membuat sebuah suling, dituntut memiliki ketrampilan yang cukup memadai, disamping memang harus menguasi teknik memainkan suling secara benar. Sehingga kehadirannya dapat berfungsi pada setiap barungan gamelan Bali, yang memiliki identitas dan keragaman bentuk dengan karakternya masing-masing.

Sebagai sebuah instrumen yang merupakan bagian, serta sebagai pelengkap dari barungan tertentu, suling belum mendapat perhatian secara serius dari kalangan seniman khususnya para pengrawit atau pemain gamelan. Mungkin menurut anggapan mereka instrumen ini hanyalah sebagai pelengkap saja, dan kehadiran suling dalam barungan tertentu bukan merupakan suatu keharusan. Padahal suling adalah instrumen yang memiliki peranan sangat penting berfungsi sebagai "pemanis nada" dalam penyajian berbagai jenis pertunjukan karawitan di Bali.

Tulisan ini akan mengkaji teknik membuat suling dari berbagai jenis suling yang ada, sehingga dapat berfungsi pada setiap barungan dalam gamelan Bali. Hal penting yang menjadi catatan, bahwa suling merupakan salah satu instrumen yang melengkapi hampir sebagian besar barungan gamelan Bali, mempunyai bentuk yang sangat sederhana dan sangat jarang orang dapat memainkan dengan baik. Kehadiran instrumen suling dalam setiap barungan, sesungguhnya adalah untuk memperkaya dan meramu khasanah gamelan itu sendiri.

\section{METODE}

Tulisan ini mempergunakan pendekatan yang bersifat kualitatif, yaitu berupaya untuk memahami dan memberikan interpretasi pada fenomena emperis yang dipadu dengan sistem logika dan nilai kebenaran dalam Seni Karawitan Bali. Mekanisme penulisannya adalah menganalisis teks yang dideskripsikan, dijadikan titik tolak untuk mengetahui jenis instrumen suling, selanjutnya menelusuri dan memahami teknik membuatnya menurut pengalaman beberapa nara sumber.

Jenis data yang dipergunakan adalah data kualitatif (non-angka). Data kualitatif berupa catatan-catatan hasil wawancara yang dilakukan terhadap beberapa orang informan, keterangan buku-buku atau referensi yang tercetak tertutama buku-buku yang berkaitan langsung dengan topik yang dikaji sebagai referensi utama atau sebagai referensi penunjang.

Sumber data yang dipergunakan terdiri dari sumber data primer dan sekunder. Sumber data primer menurut Lofland dan Lofland (Moleong, 2012: 157), adalah para informan di lapangan dan objek yang diobservasi, yang sumber informasinya akurat mendekati autentisitasnya. Sumber data sekunder diperoleh dari sumber-sumber tertulis yang menurut Gottschalk (1975: 35) dipadankan dengan dokumen. Sumber tertulis adalah referensi holistik sifatnya sebagai data pendukung dalam pendalaman kajian, baik secara teks maupun konteksnya.

\section{PEMBAHASAN}

\section{Pengertian Suling}

Suling merupakan salah satu instrumen dari gamelan Bali, dibunyikan dengan cara meniup dan memiliki berbagai jenis ukuran dari ukuran kecil dan pendek sampai ukuran besar dan panjang. Menurut klasifikasi jenis-jenis instrumen, suling dimasukkan kedalam golongan klas Aerophone, yaitu sejenis alat-alat musik yang menghasilkan bunyi karena adanya udara (angin), dengan sistem permainan yang disebut dengan ngunjal-angkihan (bahasa Bali).

Kata suling berasal dari suku kata $s u$ dan ling dengan masing-masing memiliki arti yang berlainan. Dalam bahasa Bali su berarti luwih atau baik, dan ling dalam Kamus $\mathrm{Ka}$ wi-Bali (1988:172), artinya keneh (pikiran), raos (perkataan), tetuek manah (tujuan dari pikiran). Sehingga suling dapat diartikan sebagai ungkapan atau pernyataan yang disampaikan dengan perasaan yang tulus. Dalam hubungan ini ungkapan atau pernyataan dapat diasosiasikan dengan sebuah nyanyian. Dengan demikian suling dapat diidentikkan dengan lagu atau gending, sehingga setiap orang yang mendengarnya merasa terhibur karena keindahan melodi dan alun irama yang dihasilkan, bahkan bisa terharu, bersedih dan menangis karena mendengar suara suling itu, kalau permainannya memiliki kualitas yang baik. Bahkan 
menurut ceritera orang tua, pada jaman dahulu suling biasa dipergunakan untuk memikat hati seorang gadis, sebagai perantara menginjak pada masa pertunangan.

Pada umumnya suling dibuat dari bambu, bentuknya bulat panjang seperti pipa, pada kedua ujungnya satu tertutup oleh ruas bambu dan satu ujungnya lagi dipotong sehingga terbuka untuk keluarnya udara. Pada bagian batang bambu, dibuat enam buah lubang berbentuk lingkaran dengan jarak tertentu, yang besarnya disesuaikan dengan besar bulatan bambu. Pada bagian ujung bambu yang tertutup (ruas bambu) dibuat lubang berbentuk persegi empat yang jaraknya agak jauh dari enam buah lubang yang dibuat berbentuk lingkaran. Enam lubang yang berbentuk lingkaran disebut "lubang pengatur nada" dan satu lubang berbentuk persegi empat disebut "lubang pemanis".

\section{Jenis-jenis Suling}

Suling dapat dibedakan jenisnya dalam beberapa kelompok sesuai dengan penggunaan dan ukurannya. Pengelompokan tersebut terdiri dari : 1) Suling Pagambuhan, 2) Suling Pagongan, 3) Suling Paarjan, 4) Suling Pajangeran, dan 5) Suling Pajogedan.

\section{1) Suling Pagambuhan}

Suling yang digunakan dalam Pagambuhan adalah suling yang mempunyai ukuran terbesar diantara suling yang ada dan panjangnya kira-kira mencapai satu meter. Suling Pagambuhan memegang peranan penting karena instrumen suling berfungsi sebagai pembawa lagu atau gending. Oktaf suaranya paling rendah dibandingkan dengan oktaf jenis suling yang lain, dan mempunyai teknik permainan yang cukup rumit. Besar dan panjangnya suling memerlukan nafas yang cukup kuat dan jangkauan tangan yang memadai didalam memainkannya.

\section{2) Suling Pagongan}

Suling Pagongan dapat dikategorikan sebagai suling yang sudah umum dikenal oleh lapisan masyarakat, karena asumsi orang kalau sudah menyebut Pagongan secara tidak langsung mengarah kepada barungan Gong Kebyar sebagai barungan yang mudah dipelajari dan telah dimiliki oleh hampir sebagian besar banjar dan desa adat di Bali.

Selain Gong Kebyar ada juga barungan lain yang mempergunakan suling Pagongan sebagai pelengkap barungannya, seperti ; Palegongan, Bebarongan, Semar Pagulingan termasuk Semar Pagulingan Sasih Pitu. Jenis suling yang dipakai untuk melengkapi jenis barungan tersebut memiliki standar nada yang tidak sama, sehingga perbedaan atau perubahan tetekep selalu menyesuaikan bentuk barungan dan kebutuhan lagu atau gending yang dimainkan. Suling berfungsi sebagai pemanis gending, memberi aksentuasi untuk melodi yang dimainkan lirih, serta biasa dimainkan ketika tempo gending berjalan lambat.

\section{3) Suling Paarjan}

Suling Paarjan berfungsi mengiringi atau memberi aksentuasi dan variasi terhadap tembang dalam Dramatari Arja. Dalam hal ini suling bertugas mengikuti lagu yang dilantunkan oleh penari, bahkan selalu mengadakan improvisasi yang sejalan dan seirama dengan gending yang disampaikan oleh penari Arja untuk tokoh tertentu. Tembang Paarjan lebih banyak memakai laras slendro, dan laras pelog hanya dipakai untuk mengimbangi agar adanya modes atau nuansa yang silih berganti.

Suling Paarjan disamping berfungsi sebagai pengiring tembang, berfungsi juga sebagai "pembawa melodi". Fungsi sebagai pembawa melodi biasanya pada tabuh pembukaan (show instrumental) atau untuk memulai petangkilan dalam adegan tertentu. Suling memainkan melodi secara utuh dan menuntun permainan instrumen yang lain, dimana instrumen kendang sebagai pengendali dan memberi aksen (angsel) pada bagian-bagian tertentu. Pemain Suling Paarjan yang bertugas mengiringi gending (vokal) biasanya hanya seorang saja, memainkan beberapa suling yang berbeda jenisnya. Oleh karenanya dalam Dramatari Arja dibutuhkan "pemain suling” yang betul-betul mahir dan tanggap terhadap perubahan patet atau tangga nada.

\section{4) Suling Pajangeran}

Suling Pajangeran mempunyai fungsi ganda, yaitu sebagai pemanis lagu dan sebagai pemberi standar nada. Pada Tari Janger ungkapan vokal, baik dalam bentuk nyanyian dan dialog disampaikan oleh penari secara kolektif. Demi terpeliharanya keutuhan dan keajegan lagu yang dinyanyikan perlu adanya standar nada yang biasanya dimulai oleh instrumen suling.

Pada Tari Janger penggunaan instrumen suling sampai saat ini masih bervariasi. Ada yang hanya menggunakan sebuah suling ditambah dengan perangkat instrumen yang lain, seperti : kendang krumpungan lanang-wadon, tawa-tawa, cengceng, kelenang, rebana dan gong pulu. Bentuk dan jenis yang lain ada juga memanfaatkan beberapa pasang suling ukuran menengah dan kecil yang dilengkapi dengan gender, kendang, tawa-tawa, cengceng, kelenang dan kempur.

\section{5) Suling Pajogedan}

Suling Pajogedan kebanyakan diambil dari suling Paarjan yang jumlahnya dua sampai empat buah, berfungsi untuk memaniskan gending dan membantu menjalankan melodi gending. Pajogedan atau disebut Joged Bumbung adalah perangkat gamelan yang dipergunakan untuk mengiringi tari Joged Bumbung, adalah tarian sosial masyarakat di Bali yang semata-mata berfungsi sebagai hiburan, dimana penari wanita berkostum sejenis Tari Legong yang menjawat seorang penonton untuk diajak menari. 


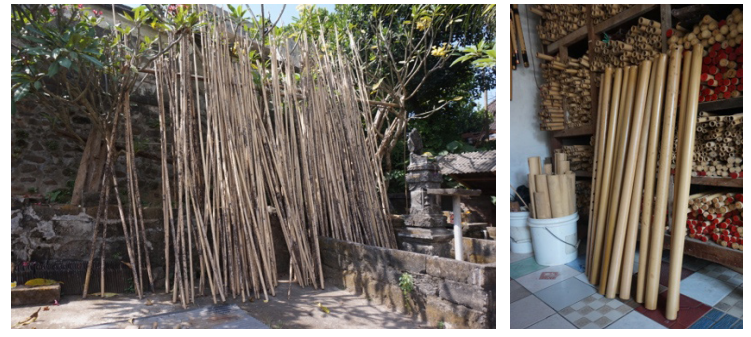

Gambar 1. Tiying jajang, bambu yang dipilih untuk suling (Sumber: Suharta, 2019)

Gamelan Joged Bumbung disebut juga gamelan Gerantang karena instrumennya yang pokok adalah gerantang, sejenis gangsa yang bilah-bilahnya dibuat dari bambu. Kelengkapan barungannya selain instrumen suling, adalah dua pasang gerantang pemade, dua pasang gerantang kantil, sebuah tawa-tawa, cengceng, kelenang, kendang gupekan dan gong pulu. Repertoar dari gamelan Pajogedan diambil dari lagu-lagu rakyat sejenis gending Janger.

\section{Tahapan Membuat Suling}

Untuk mendapatkan suara suling yang baik dan berkualitas perlu diperhatikan beberapa persyaratan tertentu, karena dalam proses membuat diperlukan adanya kecermatan dan ketelitian baik dari mulai memotong bambu, cara melubangi dan sampai kepada langkah terakhir hingga suling itu berfungsi sebagai instrumen untuk melengkapi barungan tertentu. Kualitas suara suling menurut penjelasan I Made Rana, sangat ditentukan oleh beberapa hal seperti; bahan (bambu) yang dipakai, ukuran suling dan teknik melubangi.

\section{a. Memilih Bambu}

Bambu yang baik dan dipilih untuk suling diusahakan sedapat mungkin adalah bambu Bali atau tiying Bali asli. Suara suling yang dihasilkan dari tiying Bali cukup keras dan tajam (santer). Karena kesulitan untuk memperoleh bambu yang asli, kebanyakan mempergunakan bambu jajang yang berasal dari daerah Kintamani, Kabupaten Bangli. Memiliki ciri-ciri: batangnya lurus, mulus dan mengkilat, serta sangat mudah didapat sehingga memilih bambu yang berkualitas cukup memungkinkan.

Syarat-syarat memilih bambu yang dipergunakan untuk suling, adalah : 1) dipilih bambu yang sudah tua (wayah) atau bagi yang sudah menekuni disebut nguyung (bahasa Bali), 2) batangnya agak lurus dan besar, dipilih sesuai dengan kebutuhan, dan 3) kalau dapat, usahakan bambu yang bersentuhan (mekosod) dengan bambu atau pohon lain yang ada disebelahnya.

\section{b. Waktu Memotong Bambu}

Seperti halnya dengan berbagai kegiatan yang dilaksanakan, menurut kepercayaan di Bali yang sudah diwarisi secara mentradisi, biasanya dipilih hari yang terbaik untuk jenis kegiatan tertentu, seperti mulai bercocok tanam, membuat dasar bangunan, kegiatan upacara dan sebagain- ya. Memotong bambu untuk membuat suling menurut anggapan beberapa orang boleh-boleh saja, tetapi bagi orang yang mempunyai keyakinan atau kepercayaan yang kuat, tetap tidak boleh gegabah, apalagi suling yang dibuat dipergunakan untuk dirinya atau pesanan dari sekaa tertentu. Hasil karya yang dibuat tetap dipertahankan "kualitasnya" agar dapat memberi kepuasan jiwa bagi yang sedang menikmati dan kepada para pemain diberi kekuatan serta penuh rasa percaya diri, atau sering dikatakan dengan istilah metaksu.

Hari baik (dewasa ayu) memotong bambu untuk bahan membuat suling adalah Saniscara, Kajeng, Paing, serta diusahakan memotong sebelum matahari terbit atau menjelang tengah hari (jejeg surya). Bambu yang sudah dipotong dibiarkan beberapa hari sampai daunnya rontok dan batangnya kering.

\section{c. Ukuran Membuat Suling}

Ukuran suling sangat menentukan kualitas suara suling. Suling tidak dapat dibuat menurut ukuran yang pasti, karena tergantung dari bambu yang didapat. Menurut keterangan I Wayan Roja, ukuran suling dalam artian panjang bambu yang dipotong untuk suling sangat ditentukan oleh besarnya bambu, atau dapat dikatakan bahwa untuk dibuat menjadi suling sudah membawa ukuran tersendiri, dalam bahasa Bali disebut sikut ibane.

Secara umum panjang suling sama dengan lima kali (5 x) lingkaran bambu yang dipakai. Dalam perhitungan bahwa bambu dibagi dua, yaitu dua kali (2 x) lingkaran bambu ke-atas (samping kiri) dan tiga kali (3 x) lingkaran bambu ke bawah (samping kanan). Tepat pada bagian itu mulai dibuat lubang pengatur nada sebanyak enam buah lubang menuju ke bawah (samping kanan).

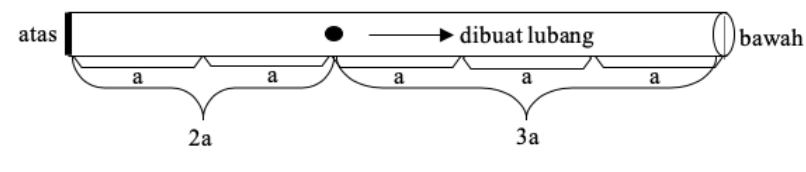

Ukuran suling yang umum.

\section{d. Teknik Melubangi}

Bambu dilubangi dengan alat-alat seperti; mutik, pahat pemuku, taji dan potongan bambu. Semua jenis alat ini sangat langka, jarang ada orang yang memiliki kecuali memiliki profesi sebagai pengrajin suling.

Lubang suling yang berbentuk lingkaran atau yang disebut lubang pengatur nada, dibuat dengan langkah-langkah sebagai berikut :

1. Bambu dilubangi dengan mutik. Mutik adalah salah satu alat yang dipakai oleh pematung (pemahat kayu), bentuknya seperti pisau agak kecil, ujungnya runcing dan tajam. Lubang dibuat dengan menukikkan ujung mutik pada bambu tempat lubang dibuat, mutik diputar-putar secara perlahan sampai lubang terbentuk. 
2. Setelah lubang terbentuk, lalu dibuat berbentuk lingkaran dengan mempergunakan pahat pemuku (pahat lengkung) sebesar lubang yang diinginkan.

3. Langkah selanjutnya lubang dihaluskan dengan taji. Taji adalah alat (senjata) yang diperguanakan oleh ayam jantan pada saat para penjudi mengadakan sabungan ayam (tajen). Untuk membuat lubang menjadi halus dang mengkilat digosok-gosokan dengan kusu ; alat khusus yang dibuat dari bambu menyerupai batangan kawat kecil sepanjang $15 \mathrm{~cm}$ yang berfungsi untuk membersihkan lubang pengatur nada.

4. Demikian juga halnya dengan lobang pengatur nada yang lain, dibuat seperti langkah-langkah di atas.

5. Langkah yang terakhir adalah menghaluskan dan membuat lubang pengatur nada mengkilat dengan mempergunakan kusu; yaitu potongan bambu yang dibuat bulat menyerupai batangan kawat kecil, panjangnya kira-kira $15 \mathrm{~cm}$ dan besarnya sama dengan besarnya lubang yang ada. Kusu diputar-putar pada lubang sehingga lubang-lubang pengatur nada kelihatan halus dan ampis. Cara ini disebut dengan ngirik.

Sedangkan membuat lubang pemanis tidak seperti membuat lubang pengatur nada, karena bentuknya persegi empat, alat yang dipakai cukup dengan mempergunakan mutik dan dihaluskan dengan taji. Tidak seperti lubang pengatur nada, sulitnya membuat lubang yang bulat. Hanya saja membuat lubang pemanis diperlukan ketelitian, kecermatan dan kesabaran untuk menafsiran tinggi-rendah suara yang akan dibuat. Jadi kualitas dan tinggi-rendah suara suling sangat ditentukan oleh lubang pemanis.

\section{Teknik dan Aturan Membuat Suling}

Bahasan mengenai cara membuat berbagai jenis suling seperti tersebut di atas dibagi menjadi tiga kelompok, yaitu : 1) membuat suling Pagambuhan, 2) membuat suling Pagongan; yang termasuk didalamnya adalah suling Palegongan, Bebarongan dan Semar Pagulingan, dan 3) membuat suling Paarjan, meliputi suling Pajangeran dan Pajogedan.

a. Membuat Suling Pagambuhan

Suling Gambuh untuk semua jenis tutupan dibuat dengan cara yang sama, baik ukuran panjang, jarak antara pengatur nada yang satu dengan yang lainnya ditentukan oleh keliling dan diameter dari bambu yang dipergunakan.

Ukuran Panjang

Panjang suling Gambuh pada umumnya di Bali menurut I Wayan Roja, mempergunakan sikut kutus atau disebut juga dengan istilah Asta pada (ukuran delapan). Ada juga yang mempergunakan sikut sanga (ukuran sembilan), akan tetapi jarang orang memakainya.

Suling memakai sikut kutus maksudnya adalah panjang suling sama dengan ukuran keliling bambu dikalikan delapan. Sedangkan sikut sanga, maksudnya adalah panjang
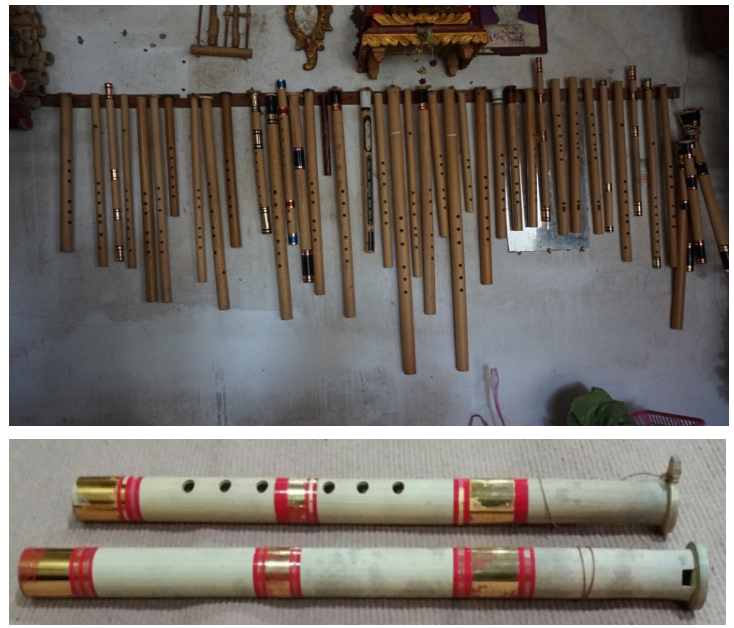

Gambar 2. Dari suling Paarjan sampai suling Pagambuhan (atas). Contoh suling Pagongan (bawah)

(Sumber: Suharta, 2019)

suling sama dengan ukuran keliling bambu dikalikan sembilan.

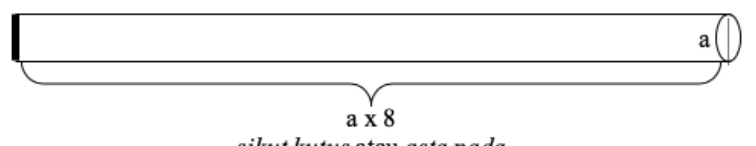

sikut kutus atau asta pada

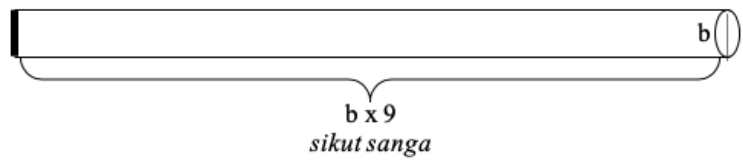

Lubang Pengatur Nada

Setelah bambu yang akan dipergunakan dapat ditentukan panjangnya, maka dilanjutkan dengan membuat lubang pengatur nada sebagai berikut :

1. Bambu yang telah ditentukan ukuran panjangnya dibagi dua (bukan di potong), tepat ditengah-tengah ukuran yang telah ditentukan dibuat lubang, dan lubang ini nantinya sebagai lubang kedua dari keenam lubang suling yang akan dibuat.

2. Ukur dalamnya lubang, dari ukuran itu didapat jarak antara lubang yang satu dengan yang lainnya, kecuali jarak lubang ke-tiga dengan lubang ke-empat sama dengan dua kali didalamnya lobang ditambah diameter lobang yang ada. Jarak ini disebut mapa-ngembang.

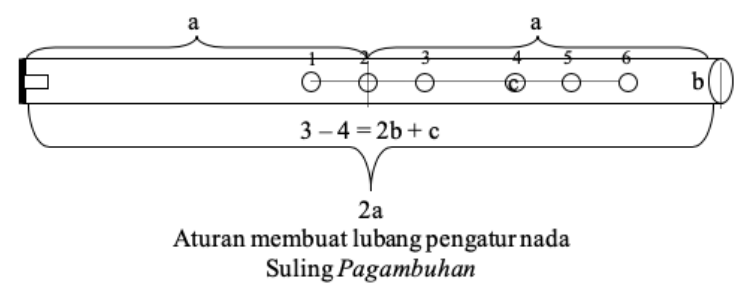

Lubang Pemanis dan Siwer

Cara membuat lubang pemanis dari semua jenis suling adalah sama, disesuaikan dengan besarnya bambu dan 


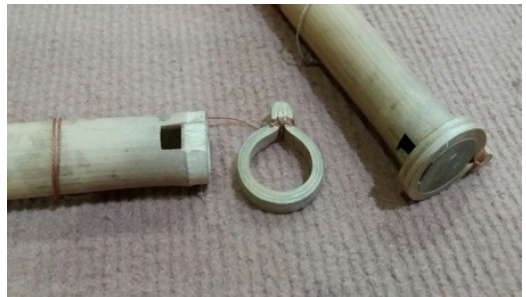

Gambar 3. Lubang pemanis dan siwer (Sumber: Suharta, 2019)

tidak ada aturan-aturan yang pasti. Lubang pemanis dibuat berbentuk persegi empat, jaraknya dari ujung bambu disesuaikan dengan takik yang dibuat. Takik adalah bagian ujung atas dari suling untuk tempatnya siwer yang juga dapat berfungsi menentukan kualitas suara suling.

Siwer adalah bagian suling yang berfungsi membuat suara suling menjadi lebih keras dan mengatur suara suling sesuai selera si-pemain. Siwer biasanya dibuat dari daun lontar, rotan dan bambu yang diikat pada kedua ujungnya dengan tali atau benang nilon, besarnya disesuaikan dengan bulatan bambu dan lebarnya sama dengan jarak lubang pemanis ke ujung suling atau takik yang dibuat.

\section{b. Membuat Suling Pagongan}

Suling Pagongan mengenal tiga jenis ukuran, yaitu : ukuran kecil, ukuran menengah dan ukuran besar. Ke-tiga jenis ukuran itu memakai standar dari nada gamelan yang ada. Ukuran kecil memakai standar nada kantil, ukuran menengah memakai standar nada pemade dan ukuran besar memakai standar nada giying atau ugal. Dari jenis ukuran itu menimbulkan perbedaan cara membuatnya. Kadang-kadang orang membuat suling untuk melengkapi barungan tertentu berpedoman pada suling ukuran kecil. Kalau suling kecil sudah cocok dengan suara gamelan atau nada-nada instrumen kantil, maka suling ukuran menengah dan ukuran besar dapat dibuat berpedoman pada suling ukuran kecil. Dapat dijamin bahwa suara suling tidak akan vals dengan suara gamelan. Ada juga dengan cara yang lain menurut aturan tertentu.

\section{1) Suling Pagongan Ukuran Kecil (tutupan-ndong)}

Namanya kecil, dari memilih bambu dan membuat lubangpun dalam ukuran kecil. Ada beberapa ketentuan membuat suling ukuran kecil, yaitu :

1. Dipilih bambu (ukuran kecil), bambu jangan dipotong atau panjangnya tidak ditentukan.

2. Bambu ditiup secara berulang-ulang dari lubang bagian bawah untuk mendapatkan kecocokan suara dengan nada ndong kantilan.

3. Kalau suara bambu dirasakan masih kurang pas, maka bambu mulai dipotong sedikit demi sedikit, sampai suaranya mendekati nada ndong tadi. Sangat diperlukan kepekaan dan kecermatan menafsirkan nada gamelan dengan suara bambu yang ditiup.

4. setelah dirasakan agak mirip dan sudah pas, bambu jangan dipotong lagi, berarti itulah ukuran panjang suling yang akan dibuat.
5. Ukur "garis tengah" lingkaran bambu, dua kali ukuran yang didapat, diukurkan pada bambu mulai dari bawah. Tepat pada ukuran itu dibuat lubang, dan lubang ini nantinya merupakan lubang pengatur nada yang ke-enam.

6. Ukur dalamnya lubang yang baru dibuat (lubang pengatur nada yang ke-enam). Lima lubang pengatur nada yang lain di buat ke-atas dengan jarak yang sama, yaitu sama dengan ukuran dalamnya lubang.

7. Langkah paling akhir dibuat lubang pemanis (berbentuk segi empat agak memanjang), dan takik tempat siwer sebagai sumber untuk mendapatkan suara suling yang sesuai dengan suara gamelan.

2) Suling Pagongan Ukuran Menengah (tutupan-ndang) Membuat suling Pagongan ukuran menengah, untuk mendapatkan suara suling yang pas dengan nada-nada gamelan, dilakukan langkah-langkah sebagai berikut :

1. Pilih bambu (ukuran sedang), jangan dipotong, atau ukuran panjang tidak ditentukan (jangan dibuat yang pasti).

2. Bambu ditiup-tiup dari lubang bagian bawah untuk mendapatkan kecocokan suara dengan nada ndang pemade.

3. Tiupan dilakukan berulang-ulang. Kalau suara bambu dirasakan masih vals, maka bambu mulai dipotong sedikit demi sedikit, sampai suaranya mendekati nada ndang yang diinginkan.

4. Setelah dirasakan agak mirip dan pas, bambu jangan dipotong lagi, berarti itulah ukuran panjang suling yang akan dibuat.

5. Ukur garis tengah bambu. Dua kali ukuran itu diukurkan pada bambu mulai dari bawah. Tepat pada ukuran itu dibuat lubang, lubang ini merupakan lubang pengatur nada yang ke-enam.

6. Ukur dalamnya lubang, lima lubang pengatur nada yang lain dibuat ke atas dengan jarak yang sama, yaitu sama dengan ukuran dalamnya lobang.

7. Langkah terakhir dibuat lubang pemanis, takik (tempat siwer) dan siwernya.

Pada umumnya jenis ukuran suling menengah (tutupan ndang) dan suling ukuran kecil (tutupan ndong) dengan teknik-teknik membuat seperti di atas, dipergunakan juga pada barungan Semar Pagulingan Saih Lima maupun Semar Pagulingan Saih Pitu, gamelan Palegongan dan gamelan Bebarongan. Jenis suling ukuran kecil dan menengah yang dipergunakan sebagai pelengkap barungan dari berbagai jenis gamelan tersebut biasanya tidak mapa-ngembang, maksudnya jarak lubang pengatur nada satu dengan lubang pengatur nada yang lainnya adalah sama (tidak ada perbedaan jarak).

\section{3) Suling Pagongan Ukuran Besar (tutupan-ndeng)}

Ada sedikit perbedaan teknik membuat suling besar dengan suling ukuran menengah maupun suling kecil dalam Pagongan. Hal ini disebabkan karena dibutuhkan bambu 
yang besar dengan ukurannya yang panjang. Secara prinsip bahwa didalam membuat suling ukuran besar umumnya mempergunakan istilah mapa-ngembang, maksudnya jarak pengatur nada satu dengan yang lainnya ada yang tidak sama. Hal ini dapat diperhatikan pada langkah-langkah sebagai berikut :

1. Dipilih bambu (ukuran besar), bambu jangan dipotong atau dibuat ukuran yang pasti.

2. Bambu ditiup-tiup dari lubang bagian bawah untuk mendapatkan kecocokan suara dengan nada ndeng-giying.

3. Tiupan dilakukan berulang-ulang. Kalau suara bambu dirasakan masih vals, maka bambu dipotong sedikit demi sedikit, sampai suaranya mendekati nada ndeng yang diinginkan.

4. Setelah dirasakan agak mirip dan pas bambu jangan dipotong lagi, berarti itulah ukuran panjang suling yang akan dibuat.

5. Ukur garis tengah bambu, empat kali ukuran itu diukurkan pada bambu mulai dari ujung bawah. Tepat pada ukuran itu dibuat lubang, lubang ini nantinya merupakan lubang pengatur nada yang ke-enam.

6. Lima lubang pengatur nada yang lain dibuat ke-atas dengan jarak sama dengan dalamnya lubang yang telah dibuat, kecuali jarak lobang ke-tiga dengan ke-empat sama dengan dua kali dalamnya lobang ditambah diameter satu lobang saja, atau yang disebut mapa-ngembang.

7. Terakhir dibuat lubang pemanis, takik dan siwernya.

\section{c. Membuat Suling Paarjan}

Cara membuat suling Paarjan jauh lebih mudah dibandingkan cara membuat suling Pagongan. Namun memainkan suling Paarjaan jauh lebih sulit dibandingkan memainkan suling Pagongan. Oleh karena itu diperlukan pemain suling yang betul-betul profesional, dalam artian menguasai gending-gending dan tanggap terhadap perubahan tangga nada (patet). Biasanya pemain suling yang mengiringi gending-gending dalam Dramatari Arja hanya seorang saja, memainkan berjenis-jenis suling dari ukuran kecil sampai ukuran besar sesuai dengan kebutuhan gending.

Secara umum suling Paarjan mengenal tiga jenis ukuran, yaitu : 1) suling ukuran kecil ; dipergunakan untuk mengiringi gending-gending yang beroktaf tinggi, seperti gending Galuh dan Condong. 2) suling ukuran sedang ; dipergunakan untuk mengiringi gending-gending yang beroktaf sedang, seperti gending Mantri dan Limbur, dan 3) suling ukuran besar ; dipergunakan untuk mengiringi gending-gending yang beroktaf rendah, seperti gending Penasar, Wijil dan Patih. Ke-tiga jenis ukuran suling tersebut dibuat dengan ketentuan sebagai berikut:

\section{1) Ukuran Panjang}

Panjang suling Paarjan tidak tentu, tergantung besar kecilnya bambu yang didapat, atau tergantung suara suling yang diinginkan. Apabila menginginkan suara suling yang agak besar atau dalam oktaf rendah maka dipilih bambu yang agak besar dan dipotong agak panjang. Kalau suara suling yang diinginkan agak kecil atau dalam oktaf tinggi, maka dipilih bambu yang agak kecil dan dibuat dengan ukuran yang pendek pula.

\section{2) Lobang Pengantar Nada}

1. Ukur keliling (lingkaran) bambu yang dipakai suling. Ukuran yang didapat dipergunakan untuk menentukan letak lubang pengatur nada yang pertama, yang diukurkan dari ujung atas.

2. Lubang pengatur nada dibuat sebanyak tujuh buah menuju ke-arah bawah dari lubang pertama sampai lubang ke-tujuh.

3. Jarak lubang pengatur nada yang satu dengan yang lainnya adalah sama, yaitu sama dengan dalamnya lubang pengatur nada yang ada.

4. Panjang suling yang dibuat tergantung besar dan kecilnya suara yang diinginkan.

Cara membuat suling Paarjan seperti di atas juga dipergunakan untuk jenis suling Pajangeran dan Pajogedan, hanya saja lubang pengatur nada suling Pajangeran dan Pajogedan dibuat sebanyak enam lubang. Khusus untuk suling Pajogedan, ke-enam lubang pengatur nada yang ada dibuat agak besar untuk mendapatkan suara suling yang agak rendah.

\section{SIMPULAN}

Secara ringkas dapat diuraikan tentang cara membuat berbagai jenis suling. Dari ukuran bambu dapat diketahui bahwa masing-masing jenis suling memiliki perbedaan dalam cara membuatnya, baik mengenai panjang ukuran suling, aturan membuat lubang pengatur nada yang satu dengan yang lainnya. Disamping perbedaan, ada juga persamaan teknik dari berbagai jenis suling yang dibuat, yaitu mengenai teknik membuat lubang pemanis. Untuk semua jenis suling, lubang pemanis dibuat berbentuk persegi empat, besarnya lubang disesuaikan dengan besarnya bambu. Demikian juga dalam membuat takik tempat siwer, dibuat sama besar dengan lingkaran bagian ukuran dalam siwer.

\section{DAFTAR RUJUKAN}

Arikunto, Suharsimi. 2002. Prosedur Penelitian Suatu Pendekatan Pratek. Edisi Revisi V. Jakarta : PT Asdi Mahastya.

Aryasa, IWM. 1983. Pengetahuan Karawitan Bali. Denpasar: Departemen Pendidikadan Kebudayaan Direktorat Jenderal Kebudayaan Proyek Pengembangan Kesenian Bali.

Bandem, I Made. 1983. Ensiklopedi Gambelan Bali. Proyek Penggalian, Pembinaan, Pengambangan, Seni Klasik Tradisional dan Kesenian Baru Pemerintah Daerah Tingkat I Bali. 
Bandem, I Made. 1986. Prakempa : Sebuah Lontar Gambelan Bali. Akademi Seni Tari Indonesia, Denpasar.

Bandem, I Made. 1991. Ubit-Ubitan : Sebuah Teknik Permainan Gambelan Bali. Sekolah Tinggi Seni Indonesia Denpasar, Ditjen Pendidikan Tinggi Depdikbud.

Dibia, I Wayan. 1999. Selayang Pandang Seni Pertunjukan Bali. Bandung : Masyarakat Seni Pertunjukan Indonesia.

Dinas Pendidikan Dasar Propinsi Dati I Bali. 1988. Kamus Kawi - Bali.

Moleong, Lexy J. 2012. Metodologi Penelitian Kualitatif. Bandung: Penerbit PT Remaja Rosdakarya.

Gottschalk, Louis. 1975. Mengerti Sejarah. terjemahan Nugroho Notosutanto. Jakarta: Universitas Indonesia.

Penitia Penyusun Kamus Bali - Indonesia. 1978. Kamus Bali - Indonesia. Denpasar : Dinas Pengajaran Daerah Tingkat I Bali.

Rembang, I Nyoman. 1973. "Gambelan Gambuh dan Gambelan Lainnya di Bali”. Kertas Kerja pada Work Shop Gambuh 25 Agustus s/d 1 September 1973 di Denpasar.

Sugriwa, I Gusti Bagus. 1973. “Aji Gurnita”(terjemahan), Senin Kliwon Uye,21 Maret.

Tantra, I Nyoman. 1991. Laporan Penelitian "Bentuk Saih, Tetekep dan Patutan dalam Gambelan Tujuah Nada di Bali”. Dilaksanakan atas Biaya Proyek Operasi dan Perawatan Fasilitas STSI Denpasar DIP No. 319/ XXIII/3/1991, Tanggal 1 Maret 1991, Direktorat Jendral Pendidikan Tinggi Departemen Pendidikan dan Kebudayaan.

\section{DAFTAR INFORMAN}

Rana, I Made - 43 tahun (16 Oktober 1976), seniman Karawitan dan pengrajin suling. Jln.Narakusuma, Gang II, No. 2, Br. Kepisah Desa Sumerta Kelod, Denpasar Timur.

Roja, I Wayan (Alm) - 88 tahun (31 Desember 1931), pemain suling, pengrajin suling dan pengrajin keris. Banjar Jeleka, Desa Batuan, Kecamatan Sukawati, Gianyar. 